\title{
Analysis and Risk Assessment of the Working Conditions \\ of a Steam Turbine Operator
}

\author{
Irina V. Andrunyak* \\ Siberian Federal University \\ Krasnoyarsk, Russian Federation
}

Received 02.07.2021, received in revised form 29.07.2021, accepted 06.08.2021

\begin{abstract}
The article analyzes the negative factors of a steam turbine operator of the 5th category using the example of the Krasnoyarsk CHP. The main factors determining the working conditions are reflected. Based on the results of a special assessment of working conditions classes (subclasses) of conditions for a steam turbine operator have been identified. The definitions and the procedure for assessing occupational risk, taking into account injuriesin hazardous areas, have been formulated, on the basis of which a tree of events of the occurrence of accidents has been built. The calculation of risk assessment of working conditions, where the main harmful factor is the impact of noise on the human body and the resulting hearing loss is proposed.
\end{abstract}

Keywords: working conditions, special assessment of working conditions, noise, sound level, hearing loss, risk assessment, accident, event tree of various accidents.

Citation: Andrunyak I. V. Analysis and risk assessment of the working conditions of a steam turbine operator, J. Sib. Fed. Univ. Eng. \& Technol., 2021, 14(5), 520-537. DOI: 10.17516/1999-494X-0330

\section{Анализ и оценка риска условий труда машиниста паровых турбин}

И.В. Андруняк

Сибирский федеральный университет Российская Федерачия, Красноярск

Аннотация. В статье проанализированы негативные факторы работы машиниста паровых турбин 5 разряда на примере Красноярской ТЭЦ. Отражены основные моменты, определяющие условия труда. По результатам специальной оценки выявлены классы (подклассы) условий труда

(C) Siberian Federal University. All rights reserved

This work is licensed under a Creative Commons Attribution-Non Commercial 4.0 International License (CC BY-NC 4.0).

* Corresponding author E-mail address: iandrunyak@sfu-kras.ru 
машиниста паровых турбин. Сформулированы определения и порядок оценки профессионального риска с учетом травматизма в опасных зонах, на основании чего построено дерево событий наступления несчастных случаев. Предложен расчет оценки риска условий труда, где основным вредным фактором является воздействие шума на организм человека и вследствие этого потеря слуха.

Ключевые слова: условия труда, специальная оценка условий труда, шум, уровень звука, потеря слуха, оценка риска, несчастный случай, дерево событий наступления различных несчастных случаев.

Цитирование: Андруняк, И. В. Анализ и оценка риска условий труда машиниста паровых турбин / И. В. Андруняк // Журн. Сиб. федер. ун-та. Техника и технологии, 2021, 14(5). С. 520-537. DOI: 10.17516/1999-494X-0330

\section{Введение}

Научно-технический прогресс оказывает противоречивое воздействие на изменение условий труда. С одной стороны, в производственную сферу внедряются новые технологические процессы и материалы, которые могут оказать неблагоприятное воздействие на здоровье человека, с другой - создаются все более совершенные средства защиты и улучшения производственной среды. Механизация и автоматизация производства снижают физическую нагрузку, но повышает постоянное нервное напряжение. Условия труда влияют на формирование общественного мнения о конкретных профессиях (привлекательность, престиж и др.) и играют значительную роль в их выборе. Условия труда являются одним из основных факторов, определяющих уровень удовлетворенности работой [1].

Работа машиниста паровой турбины связана с рядом факторов, которые могут негативно отразиться на здоровье человека. Прежде всего, это такие опасные и вредные производственные факторы, как высокая температура рабочих поверхностей и воздуха в зоне работы, шум, вибрация, электрический ток и вращающиеся механизмы. При высокой температуре в зоне работы у человека начинается сильное потоотделение, которое может привести к обезвоживанию, ослаблению внимания, плохой координации движений, замедлению реакций, что сказывается на работоспособности [2].

Главным негативным фактором работы машиниста паровых турбин является шум, который оказывает негативное влияние на психику и может привести к нарушению периферического кровообращения, а также он может спровоцировать тугоухость - одно из самых распространенных профессиональных заболеваний. Еще один фактор - это вибрации, которые способствуют развитию преждевременной усталости и, как следствие, снижению производительности труда, а также возникновению вибрационной болезни. Также воздействие электрического тока может вызвать различные виды травм или вовсе стать причиной летального исхода. Причинить работнику вред в виде раздавливания, ранения, запутывания, затягивания, удара или колотых ран могут вращающиеся механизмы на производстве.

Условия труда - совокупность факторов производственной среды и трудового процесса, оказывающих влияние на работоспособность и здоровье работника [3]. На самом деле классификаций факторов условий труда существует несколько. Большинство из их - это классификации с вариантами психологического формата, в основном исключающие социальные факторы и основанные на социологическом подходе [4].

$$
-521-
$$


Самой полной является классификация НИИ труда, которая в полной мере охватывает все основные группы элементов, составляющих совокупность условий труда (рис. 1). Все элементы, которые определяют условия труда, описываются единицами измерения и характером воздействия на человека.

В зоне обслуживания машиниста паровой турбины существует множество опасных и вредных производственных факторов. Помещение турбинного цеха характеризуется:

$\checkmark$ повышенной температурой;

$\checkmark$ наличием теплового излучения;

$\checkmark$ повышенной влажностью;

$\checkmark$ повышенным шумовым воздействием.

Для защиты от опасных и вредных факторов машинисту паровых турбин бесплатно выдаются средства индивидуальной защиты (костюм для защиты от общепромышленных загрязнений и механических воздействий, кожаные ботинки с защитным подноском, перчатки с полимерным покрытием, противошумные наушники, защитная каска, защитные очки, средства индивидуальной защиты органов дыхания).

При обслуживании вращающихся механизмов не должно быть развевающихся частей одежды, которые могут быть захвачены движущимися частями механизмов. При необходимости нахождения вблизи горячих частей оборудования следует принять меры по защите от ожогов и действия высоких температур (ограждение оборудования, вентиляция, теплая спецодежда). Если уровень шума высокий, то необходимо использовать противошумные защитные средства (наушники, беруши). Если воздух в рабочей зоне запылен, то работать нужно в противопылевом респираторе («Лепесток» и др.) [5].

\section{1. Специальная оценка условий труда}

Специальная оценка условий труда является единым комплексом последовательно осуществляемых мероприятий по идентификации вредных и (или) опасных факторов производственной среды и трудового процесса и определению уровня их воздействия на работника с учетом отклонения их фактических значений от установленных, уполномоченным Правительством Российской Федерации федеральным органом исполнительной власти нормативов (гигиенических нормативов) условий труда и применения средств индивидуальной и коллективной защиты работников [6, 7].

Согласно Федеральному закону от 28.12.2013 N426-Ф3 «О специальной оценке условий труда» условия труда по степени вредности и (или) опасности подразделяются на четыре класса - оптимальные (1 класс), допустимые (2 класс), вредные (3 класс: 3.1, 3.2, 3.3, 3.4) и опасные условия труда (4 класс). По результатам проведения специальной оценки условий труда (СОУТ) устанавливаются классы (подклассы) условий труда на рабочих местах.

По данным Всемирной организации здравоохранения, 4-7 \% населения в мире страдают определенными нарушениями слуха; общение с другими людьми затруднено для 1,5-2,0%. Потеря слуха обычно является следствием воздействия шума на организм человека. Шум - это любой звук, который может вызвать потерю слуха или быть вредным для здоровья или опасным в другом отношении.

Рекомендации по улучшению условий труда: для поддержания высокой работоспособности и снижения неблагоприятного воздействия нагревающего микроклимата рекомендуется 


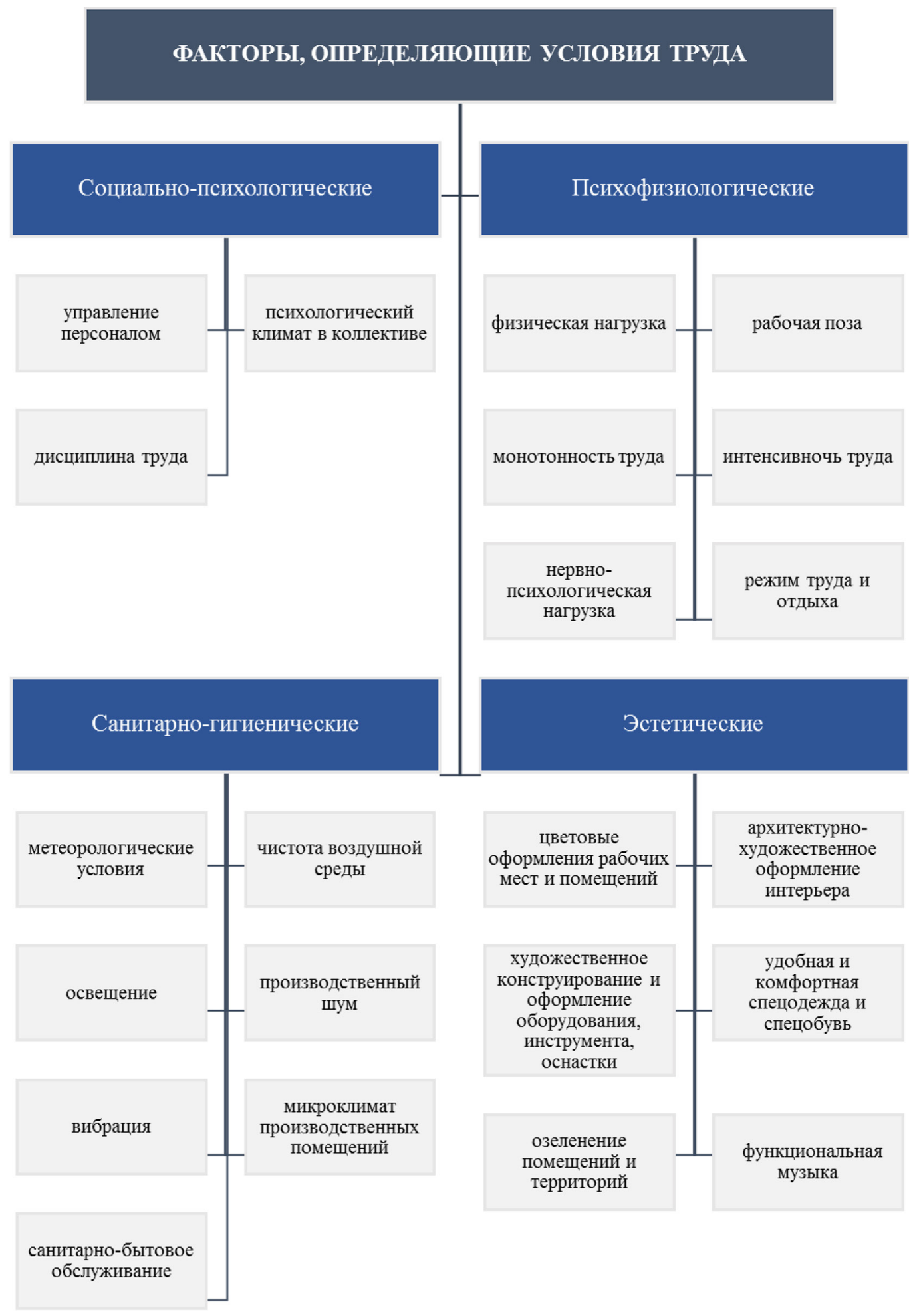

Рис. 1. Факторы, определяющие условия труда

Fig. 1. Factors determiningработы working conditions 
разработать режим труда и отдыха в соответствии с МР 2.2.8.0017-10. В настоящее время согласно МР 2.2.9.2128-06 «Комплексная профилактика развития перенапряжения и профессиональных заболеваний спины у работников физического труда» предприятиям предлагается разработать режим труда и отдыха для снижения отрицательного воздействия. Например, для уменьшения вредного воздействия шума рекомендуется ограничить суммарное время пребывания в помещениях с повышенным уровнем шума, разработать рациональные режимы труда и отдыха, использовать средства индивидуальной защиты органов слуха, контролировать их применение работниками, выполнить иные организационные и организационно-технические мероприятия $[8,9]$.

Порядок исследования (испытания) и измерения вредных и (или) опасных производственных факторов и оформления результатов проведения специальной оценки условий труда следующий: проведение исследований; отнесение условий труда к классам (подклассам) условий труда; оформление результатов исследований и оценки условий труда $[10,11]$.

Формирование результатов СОУТ (специальная оценка условий труда): 1. Сведения об организации, проводящей СОУТ, с приложением копий документов, подтверждающих ее соответствие установленным требованиям. 2. Перечень рабочих мест с указанием вредных факторов. 3. Карты СОУТ. 4. Протоколы исследований и измерений. 5. Протоколы оценки эффективности средств индивидуальной защиты. 6. Сводная ведомость СОУТ. 7. Перечень мероприятий по улучшению условий труда. 8. Заключение эксперта организации, проводящей СОУТ.

Информирование о результатах СОУТ: 1. Ознакомление работников с результатами СОУТ. 2. Размещение на сайте организации сводных данных в части установления классов, подклассов условий труда и перечня мероприятий по улучшению условий труда. 3. Представление данных в территориальный орган Роструда. 4. Передача данных о результатах проведения СОУТ в Федеральную информационную систему.

По результатам проведения СОУТ на Красноярской ТЭЦ в турбинном цехе выявлены классы (подклассы) условий труда машиниста паровых турбин 5 разряда, итоговый класс УТ (условия труда) составляет 3.2 (табл. 1). Проблемным и основным фактором для машиниста является производственный шум [12].

\section{2. Гарантии и льготы работникам с вредными и опасными условиями труда}

По результатам специальной оценки условий труда работникам, связанным с вредными и (или) опасными условиями труда, определяются гарантии и компенсации, которые представлены в табл 2. Гарантии и компенсации работникам, непосредственно занятым на работах с вредными и (или) опасными условиями труда, могут устанавливаться коллективным договором и локальным нормативным актом с учетом финансово-экономического положения работодателя [13].

Оплата труда работников, занятых на работах с вредными и (или) опасными условиями труда, устанавливается в повышенном размере. Минимальный размер повышения оплаты труда работникам, занятым на работах с вредными и (или) опасными условиями труда, составляет 4 \% тарифной ставки (оклада), установленной для различных видов работ с нормальными условиями труда. Конкретные размеры повышения оплаты труда устанавливаются работодате- 
Таблица 1. Классы (подклассы) условий труда

Table 1. Classes (subclasses) of working conditions

\begin{tabular}{|c|c|c|}
\hline $\begin{array}{l}\text { Наименование } \\
\text { рабочего места }\end{array}$ & \multicolumn{2}{|l|}{ Классы (подклассы) условий труда } \\
\hline \multirow{22}{*}{ 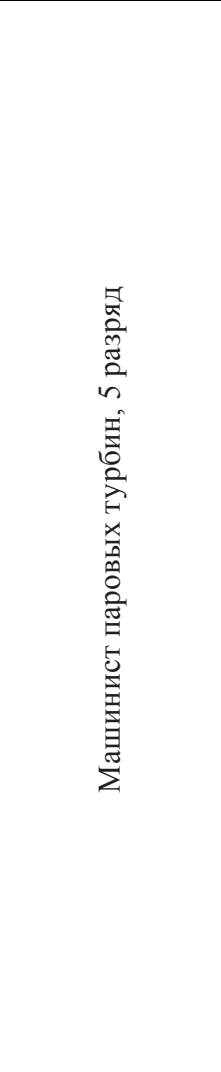 } & Химический & 2 \\
\hline & Биологический & - \\
\hline & Аэрозоли & - \\
\hline & Шум & 3.2 \\
\hline & Инфразвук & 2 \\
\hline & Ультразвук & - \\
\hline & Вибрация общая & 2 \\
\hline & Вибрация локальная & - \\
\hline & Неионизирующее излучение & 2 \\
\hline & Ионизирующее излучение & - \\
\hline & Микроклимат & 3.1 \\
\hline & Световая среда & - \\
\hline & Тяжесть ТП (трудового процесса) & 3.1 \\
\hline & Напряженность ТП & 2. \\
\hline & Итоговый класс (подкласс) УТ & 3.2 \\
\hline & Итоговый класс (подкласс) УТ с учетом эффективного применения СИЗ & 3.2 \\
\hline & Повышенный размер оплаты труда & да \\
\hline & Ежегодный доп. оплачиваемый отпуск & да \\
\hline & Сокращенная продолжительность рабочего времени & нет \\
\hline & Молоко или др. пищевые продукты & нет \\
\hline & Лечебно-профилактическое питание & нет \\
\hline & Льготное пенсионное обеспечение & да \\
\hline
\end{tabular}

лем с учетом мнения представительного органа работников в порядке, установленном ст. 372 настоящего Кодекса для принятия локальных нормативных актов, либо коллективным договором, трудовым договором [13].

Сохранение гарантий и компенсаций, ранее установленных на основании такой аттестации, предполагается только в одном случае. Согласно ч. 3 ст. 15 Закона № 421-Ф3 в отношении работников, занятых на работах с вредными и (или) опасными условиями труда, порядок и условия осуществления компенсационных мер не могут быть ухудшены по сравнению с порядком и условиями, фактически реализуемыми в отношении таких работников компенсационных мер по состоянию на 1 января 2014 г. при условии сохранения соответствующих условий труда на рабочем месте, явившихся основанием для назначения реализуемых компенсационных мер. Верховный Суд РФ, применяя нормы названной статьи в решении от 14 октября 2014 г. № АКПИ14-918, пришел к выводу, что гарантии и компенсации работникам, на рабочих местах которых по результатам проведенной до 31 декабря 2013 г. аттестации рабочих мест по условиям труда установлены вредные (опасные) условия труда, должны сохраняться до улучшения условий труда на данных рабочих местах.

$$
-525-
$$


Таблица 2. Гарантии и компенсации, предоставляемые работнику (работникам), занятым на данном рабочем месте

Table 2. Guarantees and compensations provided to the employee (employees) employed at this workplace

\begin{tabular}{|c|c|c|c|}
\hline \multirow[b]{2}{*}{$\begin{array}{l}\text { Виды гарантий } \\
\text { и компенсаций }\end{array}$} & \multirow[b]{2}{*}{$\begin{array}{c}\text { Фактическое } \\
\text { наличие }\end{array}$} & \multicolumn{2}{|c|}{ По результатам оценки условий труда } \\
\hline & & $\begin{array}{c}\text { Необходимость } \\
\text { в установлении } \\
\text { (да, нет) }\end{array}$ & Основание \\
\hline $\begin{array}{l}\text { Повышенная оплата } \\
\text { труда работников }\end{array}$ & да & да & $\begin{array}{l}\text { «Трудовой кодекс Российской Федерации» } \\
\text { от 30.12.2001 № 197-ФЗ (в ред. посл. изм. } \\
\text { и доп.). } \\
\text { Статья 147. Оплата труда работников, } \\
\text { занятых на работах с вредными и (или) } \\
\text { опасными условиями труда }\end{array}$ \\
\hline $\begin{array}{l}\text { Ежегодный } \\
\text { дополнительный } \\
\text { оплачиваемый отпуск }\end{array}$ & да & да & $\begin{array}{l}\text { «Трудовой кодекс Российской Федерации» } \\
\text { от 30.12.2001 № 197-ФЗ (в ред. посл. изм. } \\
\text { и доп.). } \\
\text { Статья 117. Ежегодный дополнительный } \\
\text { оплачиваемый отпуск работникам, занятым } \\
\text { на работах с вредными и (или) опасными } \\
\text { условиями труда. }\end{array}$ \\
\hline $\begin{array}{l}\text { Молоко или другие } \\
\text { равноценные пищевые } \\
\text { продукты }\end{array}$ & да & нет & Отсутствует \\
\hline $\begin{array}{l}\text { Право на досрочное } \\
\text { назначение страховой } \\
\text { пенсии }\end{array}$ & да & да & $\begin{array}{l}\text { Вид производства - ХІІІ. Электростанции, } \\
\text { энергопоезда, паросиловое хозяйство } \\
2140000 \mathrm{a}-13971 \\
\text { Машинисты паровых турбин }\end{array}$ \\
\hline $\begin{array}{l}\text { Проведение } \\
\text { медицинских осмотров }\end{array}$ & да & да & $\begin{array}{l}\text { Часть первая, Статья 213, Глава 34, Раздел Х, } \\
\text { Часть III, «Трудовой кодекс Российской } \\
\text { Федерации» от } 30.12 .2001 \text { № 197-Ф3 (в ред. } \\
\text { посл. изм. и доп.) }\end{array}$ \\
\hline
\end{tabular}

\section{3. Оценка профессионального риска}

На сегодняшний день расчет рисков является обязательным условием при учете безопасности условий труда. В соответствии с п. 8 Типового положения о СУОТ управление профессиональными рисками (табл. 3) - одна из процедур, направленных на достижение целей работодателя в области охраны труда (утвержден и введен в действие Приказом Федерального агентства по техническому регулированию и метрологии от 1 декабря 2011 г. № 680-ст).

Согласно типовому положению о СУОТ, утвержденному приказом Минтруда России от 19.08.2016 № 438н, работодатель должен: определить порядок реализации мероприятий по управлению профессиональными рисками $\rightarrow$ выявление опасностей $\rightarrow$ оценить уровень профессиональных рисков $\rightarrow$ снизить уровень профессиональных рисков.

Выявление опасностей, которые могут причинить вред жизни или здоровью работников, является первым и основным этапом процесса управления рисками. Для выявления опасностей необходимо определить все источники, ситуации, действия или их комбинации, которые могут привести к травмам или ухудшению здоровья сотрудников. Они называются факторами риска $[14,15]$. 
Таблица 3. Определения профессионального риска

Table 3. Definitions of occupational risk

\begin{tabular}{|c|c|}
\hline Определение & Источник \\
\hline $\begin{array}{l}\text { Профессиональный риск - вероятность причинения вреда здоровью в результате } \\
\text { воздействия вредных и (или) опасных производственных факторов при } \\
\text { исполнении работником обязанностей по трудовому договору или в иных случаях, } \\
\text { установленных настоящим Кодексом, другими федеральными законами }\end{array}$ & $\begin{array}{l}\text { Трудовой кодекс } \\
\text { РФ № } 197 \text { ФЗ [3] }\end{array}$ \\
\hline $\begin{array}{l}\text { Профессиональный риск - вероятность повреждения (утраты) здоровья } \\
\text { или смерти застрахованного, связанная с исполнением им обязанностей } \\
\text { по трудовому договору (контракту) }\end{array}$ & $\begin{array}{l}\text { Фонд социального } \\
\text { страхования РФ } \\
{[16]}\end{array}$ \\
\hline $\begin{array}{l}\text { Профессиональный риск - это вероятность повреждения (утраты) здоровья } \\
\text { или смерти работника в зависимости от состояния условий труда, опасных } \\
\text { производственных факторов и данных о случаях производственного } \\
\text { травматизма и профессиональных заболеваний на рабочем месте }\end{array}$ & $\begin{array}{l}\text { Международная } \\
\text { организация } \\
\text { по стандартизации } \\
\text { ИСО [17] }\end{array}$ \\
\hline $\begin{array}{l}\text { Профессиональный риск - вероятность причинения ущерба репродуктивной } \\
\text { функции работника, мужчины или женщины (а также развитию } \\
\text { внутриутробного плода и здоровью новорожденного в период кормления } \\
\text { грудью), в связи с исполнением трудовых обязанностей }\end{array}$ & $\begin{array}{l}\text { Российская } \\
\text { энциклопедия } \\
\text { по медицине труда } \\
{[18]}\end{array}$ \\
\hline
\end{tabular}

Оценить уровень профриска - значит определить его величину и тяжесть возможных последствий. Для оценки профессиональных рисков на практике чаще всего применяется универсальный и эффективный метод - Файна-Кинни [17]. Он заключается в том, что для каждой выявленной опасности рассчитывается индекс профессионального риска. Идея метода Файна и Кинни заключается в оценке индивидуальных рисков как произведение трех составляющих - воздействия, вероятности и последствия наступления события $\mathrm{P}=$ Воз. $\times$ Вер $\times$ Посл. В каждом конкретном случае определяется, каким образом то или иное нарушение требований охраны труда может привести к производственной травме или профессиональному заболеванию. Рассматриваются все стадии работ: от процесса подготовки до стадии их выполнения и завершения. При оценке последствий желательно выбирать наиболее худший случай - это позволяет более точно оценить риски.

Целью определенияи оценки рисков является их устранение, а в тех случаях, когда это невозможно, следует разработать меры управления и контроля. Меры по корректировке рисков подбираются в зависимости от реальной ситуации в организации. Если у работодателя нет денег на новое оборудование, то нужно использовать менее затратные методы снижения уровня риска. Например, заменить только несколько конструктивных элементов, которые обеспечат защиту от травм. Оценку рисков выполняют прямыми и косвенными методами. Порядок оценки рисков представлен на рис. 2.

Уровень риска оценивается каждый раз, когда вносятся какие-либо изменения, влияющие на факторы риска, такие как новый процесс или оборудование. После того как меры, рекомендованные экспертами и одобренные работодателем, будут реализованы, уровень риска должен быть повторно оценен для определения необходимости разработки дополнительных корректирующих мер.

Определение, анализ и сравнительная оценка профессионального риска травматизма в опасных зонах, при выполнении опасных видов работ, потенциальных причин травматизма на рабочем месте предлагается определять с использованием метода экспертных оценок (метод Дельфи) - путем заполнения анкет [14]. Главная цель оценки профессионального риска -

$$
-527-
$$




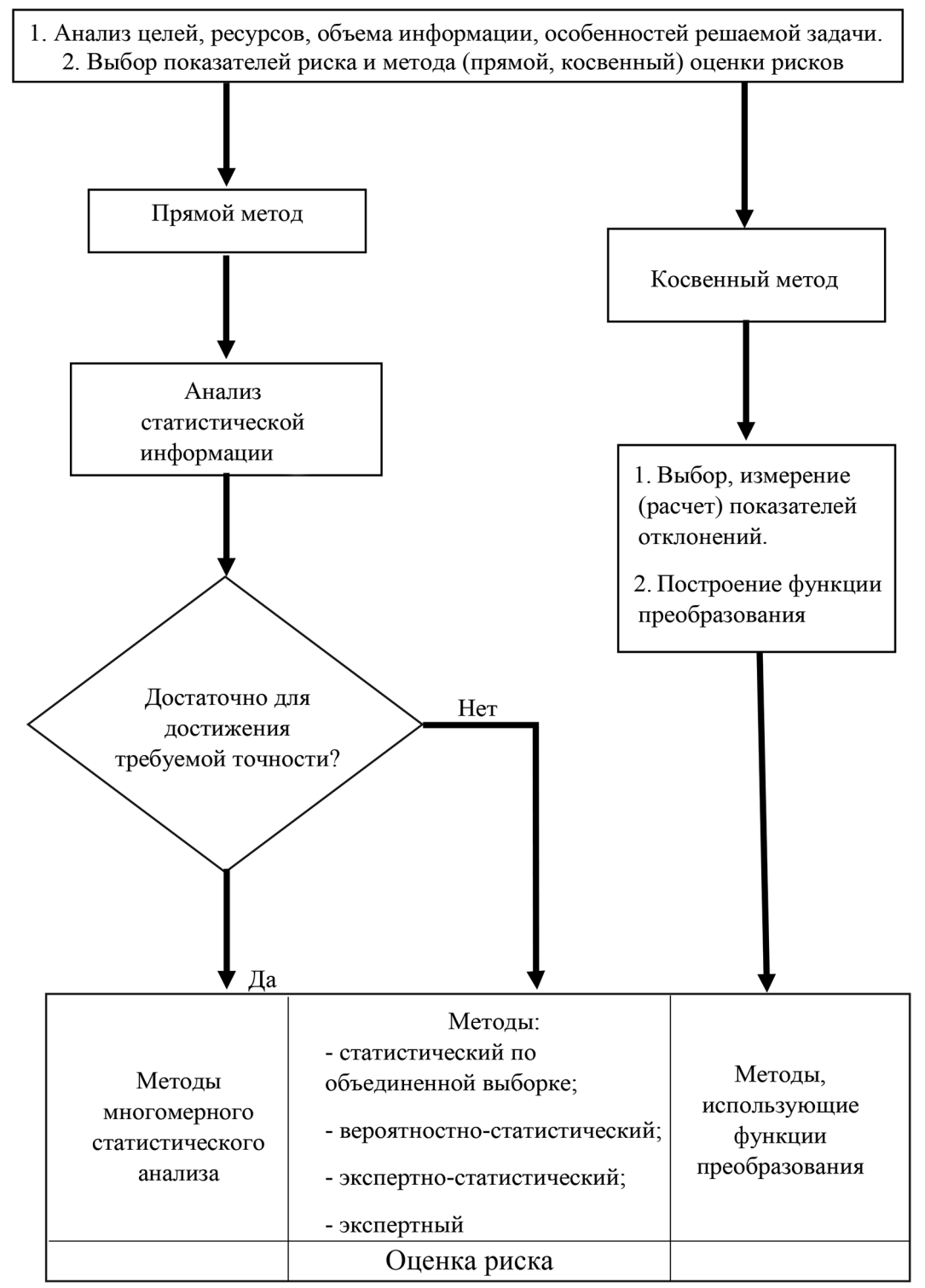

Рис. 2. Порядок оценки рисков

Fig. 2. Risk assessment procedure

предоставление на базе объективных данных информации, которая необходима для принятия обоснованного решения о путях снижения риска. Деятельность по оценке профессиональных рисков осуществляется в рамках деятельности комитета (комиссии) по охране труда.

\section{4. Расчеты профессионального риска потери слуха}

Главный вредный эффект при воздействии шума на организм человека - риск потери слуха (ПС). Основными определяющими факторами риска в формировании ПС выступают: экспозиция шума, возраст, наличие симптома белых пальцев, потребление лекарств и степень холестерина. 
По данным проведения специальной оценки условий труда была рассчитана сменная доза шума для машиниста паровых турбин 5 разряда. Методика расчета риска потери слуха от шума соответствует положениям стандарта ИСО [19], которая учитывает пол, возраст, уровень шума и стаж работы в нем.

Сменную дозу определяют по соотношению [20]:

$$
\text { Д }=\Sigma U_{i} \cdot t_{i} / U_{\text {доп }} \cdot t_{\text {доп }}
$$

где $U_{i}$ - значение кинетического параметра (звукового давления, виброускорения и т. п.); $t_{i}-$ время действия; $U_{\text {до }}$ равно ПДУ шума; $t_{\text {доп }}=8$.

Шум уровнем 84 дБ(А) действует в течение 12 ч в смену, тогда эквивалентный уровень за смену будет равен 84-0 = 84 дБ(А). При ПДУ шума, равном 80 дБ(А), превышение нормы составит 84-80 = 4 дБ(А), или по дозной оценке (табл. 4) 2,5 раза.

Шум уровнем 84 дБ(А) действует в течение 6 ч в смену, тогда эквивалентный уровень за смену будет равен 84-6 = 78 дБ(А). При ПДУ (предельно допустимый уровень) шума, равном 80 дБ(А), превышение нормы составит 78-80=-2 дБ(А), или по дозной оценке (табл. 5) 0,63 раза.

Расчет безопасной стажевой дозы шума. Уровень шума за смену составляет $=84$ дБ. При ПДУ $=80$ дБ и расчетном стаже 40 лет (поправка для стажа 40 лет составляет 16 дБ) безопасная стажевая доза равна $80+16=96$ дБ.

В рассматриваемом случае безопасный стаж работы с уровнем 84 дБ составит: 96-84= $=12$ дБ, чему по табл. 4 соответствует стаж 15 лет.

Пример оценки вероятности ПС и трудоспособности вследствие воздействия шума.

1. По возрасту:

$$
\begin{gathered}
\mathrm{H}_{90,60}=[(-2)+(-1)+7] / 3=-3,3 \text { дБ. } \\
\mathrm{H}_{50,60}=(7+12+28) / 3=15,7 \text { дБ. } \\
\mathrm{H}_{10,60}=(19+29+55) / 3=34,3 \text { дБ. }
\end{gathered}
$$

2. По стажу:

$$
\begin{gathered}
\mathrm{N}_{90,40}=(0+4+11) / 3=5 \text { дБ. } \\
\mathrm{N}_{50,40}=(0+6+15) / 3=7 \text { дБ. } \\
\mathrm{N}_{10,40}=(0+10+20) / 3=10 \text { дБ. }
\end{gathered}
$$

3. Порог слышимости:

$$
\begin{gathered}
\mathrm{H}^{\prime}{ }_{90}=(-3,3)+5=17 \text { дБ (І степень). } \\
\mathrm{H}^{\prime}{ }_{50}=15,7+7=22,7 \text { дБ (ІІ степень). } \\
\mathrm{H}_{10}^{\prime}=34,3+10=44,3 \text { дБ (ІІІ степень). }
\end{gathered}
$$

По данным табл. 6, с использованием метода экстраполяции вероятность развития I, II, III степеней ПС в данном случае равна 82, 53 и $33 \%$, т. е. наиболее вероятно, что у рабочего может быть II-III степень ПС или, что одно и то же, профессиональный риск ПС II-III степени (умеренное и значительное снижение слуха).

\section{5. Проведение оценки профессиональных рисков}

Выявление опасностей является начальным и самым важным этапом оценки рисков [21, 22], которые могут причинить вред здоровью и безопасности людей. При этом необходимо найти ответы на следующие вопросы.

$$
-529-
$$


Таблица 4. Соотношение между разностью уровней звука (фактические минус допустимые) и отношение доз шума

Table 4. The ratio between the difference in sound levels (actual minus permissible) and the ratio of noise doses

\begin{tabular}{|c|c|c|c|}
\hline Разность уровней в дБ & Отношение доз & Разность уровней в дБ & Отношение доз \\
\hline-10 & 0,1 & 10 & 10 \\
\hline-9 & 0,12 & 11 & 12 \\
\hline-8 & 0,16 & 12 & 16 \\
\hline-7 & 0,2 & 13 & 20 \\
\hline-6 & 0,25 & 14 & 25 \\
\hline-5 & 0,32 & 15 & 32 \\
\hline-4 & 0,4 & 16 & 40 \\
\hline-3 & 0,5 & 17 & 50 \\
\hline-2 & 0,63 & 18 & 63 \\
\hline-1 & 0,8 & 19 & 80 \\
\hline 0 & 1 & 20 & 100 \\
\hline 1 & 1,2 & 21 & 120 \\
\hline 2 & 1,6 & 22 & 160 \\
\hline 3 & 2 & 23 & 200 \\
\hline 4 & 2,5 & 24 & 250 \\
\hline 5 & 3,2 & 25 & 320 \\
\hline 6 & 4 & 26 & 400 \\
\hline 7 & 5 & 27 & 500 \\
\hline 8 & 6,3 & 28 & 630 \\
\hline 9 & 8 & 29 & 800 \\
\hline 10 & 10 & 30 & 1000 \\
\hline
\end{tabular}

Таблица 5. Поправка для расчета стажевой дозы

Table 5. Correction for calculating the experience dose

\begin{tabular}{|l|l|l|l|l|l|l|l|l|l|l|l|l|l|}
\hline Стаж, лет & 1 & 2 & 3 & 4 & 5 & 8 & 10 & 12 & 15 & 20 & 25 & 30 & 40 \\
\hline Поправки, дБ & 0 & 3 & 5 & 6 & 7 & 8 & 10 & 11 & 12 & 13 & 14 & 15 & 16 \\
\hline
\end{tabular}

Для определения опасностей необходимо выполнить комплексную проверку, включая следующее:

- производственная деятельность, которая может оказывать воздействие на здоровье человека, безопасность и окружающую среду, включая работы, выполняемые подрядчиками на территории производства или от его имени;

- регулярная или плановая ежедневная деятельность, периодические работы, специальные (внерегламентные), но планируемые действия, а также возможные аварийные ситуации;

- рабочее место, здания, оборудование и системы обеспечения работ; 
Таблица 6. Вероятность развития профессиональной потери слуха, \%

Table 6.The likelihood of developing professional hearing loss, $\%$

\begin{tabular}{|c|c|c|c|c|c|c|c|c|c|c|c|c|}
\hline \multirow{4}{*}{ 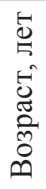 } & \multicolumn{12}{|c|}{ Стаж работы, лет } \\
\hline & \multicolumn{3}{|c|}{10} & \multicolumn{3}{|c|}{20} & \multicolumn{3}{|c|}{30} & \multicolumn{3}{|c|}{40} \\
\hline & \multicolumn{12}{|c|}{ Степени снижения слуха } \\
\hline & I & II & III & I & II & III & I & II & III & I & II & III \\
\hline \multicolumn{13}{|c|}{$\mathrm{L}_{\text {аэкв }}=90$ дБ (А) } \\
\hline 30 & 12 & 0 & 0 & & & & & & & & & \\
\hline 40 & 22 & 0 & 0 & 25 & 0 & 0 & & & & & & \\
\hline 50 & 33 & 0 & 0 & 35 & 3 & 0 & 37 & 3 & 0 & & & \\
\hline 60 & 44 & 6 & 0 & 46 & 9 & 0 & 48 & 10 & 0 & & & \\
\hline \multicolumn{13}{|c|}{$\mathrm{L}_{\text {аэкв }}=100$ дБ (А) } \\
\hline 30 & 39 & 17 & 0 & & & & & & & & & \\
\hline 40 & 47 & 25 & 5 & 62 & 32 & 6 & & & & & & \\
\hline 50 & 50 & 28 & 7 & 62 & 36 & 15 & 68 & 41 & 20 & & & \\
\hline 60 & 60 & 37 & 19 & 71 & 44 & 25 & 76 & 48 & 30 & 82 & 53 & 33 \\
\hline
\end{tabular}

- изменения или предложенные изменения в деятельности, включая проектирование либо внедрение новых процессов, нового или модернизированного оборудования и процедур, а также организационные изменения;

- применимое законодательство и нормативно-правовые акты, имеющие отношение к выявленным рискам, а также внедрению и реализации механизмов управления;

- консультация с сотрудниками и ключевыми заинтересованными лицами;

- анализ рабочих материалов и схем технологических процессов, включая мероприятия, осуществляемые за пределами объекта;

- результаты наблюдений, проверок и аудитов в области охраны труда;

- анализ безопасности рабочих мест и существующих опасностей;

- отчеты о происшествиях;

- механическая целостность (многочисленные неполадки в работе оборудования).

Необходимо учитывать опасные ситуации, возникающие как при обычном ходе рабочего процесса, так и в исключительных и редких ситуациях. Исключительными ситуациями можно считать, например:

- использование временных работников и практикантов,

- сверхурочные работы и ночные смены,

- изменения в трудовом процессе и ремонты,

- уборка, ремонт и обслуживание оборудования во время работы.

Факторы опасности можно легко распознать, делая контрольный обход рабочего места, скрупулезно выявляя все проделанные операции и действия, наблюдая за ходом работы и опрашивая работников. Во время записи факторов опасности следует фиксировать также все уточнения, касающиеся этого вопроса, комментарии и вопросы. Такие записи облегчают дальнейшую работу. Помимо анкет для распознавания опасностей можно использовать зарисовки, 
фотографии. Видеосъемка также помогает заметить возникающие в процессе труда опасности. Далее необходимо зафиксировать выявленные опасности в соответствующих реестрах по оценке рисков. Можно использовать объединенный реестр опасностей или вести отдельные реестры опасностей.

Следует внести наиболее полные сведения обо всех выявленных опасностях для последующей оценки, классификации и управления профессиональными рисками. Например, можно указать объект, на котором была обнаружена такая опасность, конкретные рабочие области или рабочее состояние (стандартные операционные условия, аварийные условия и так далее), связанные с опасностью.

На основе данных реестра по оценке рисков построено дерево событий наступления различных несчастных случаев (НС) (рис. 3-5) [23]. На рис. 3 видно, что взрыв может произойти из-за того, что оборудование находится под давлением. Невозможность ликвидации взрыва равна 0,6 , а невозможность эвакуации равна 0,4 .

На рис. 4 представлен несчастный случай из-за неисправности электрического оборудования, получение травмы равно 0,32 , отсутствие травмы 0,68 , т. е. наиболее вероятно, что работник не получит травму. Получение ожога равно 0,24 , а отсутствие ожога равно 0,76 .

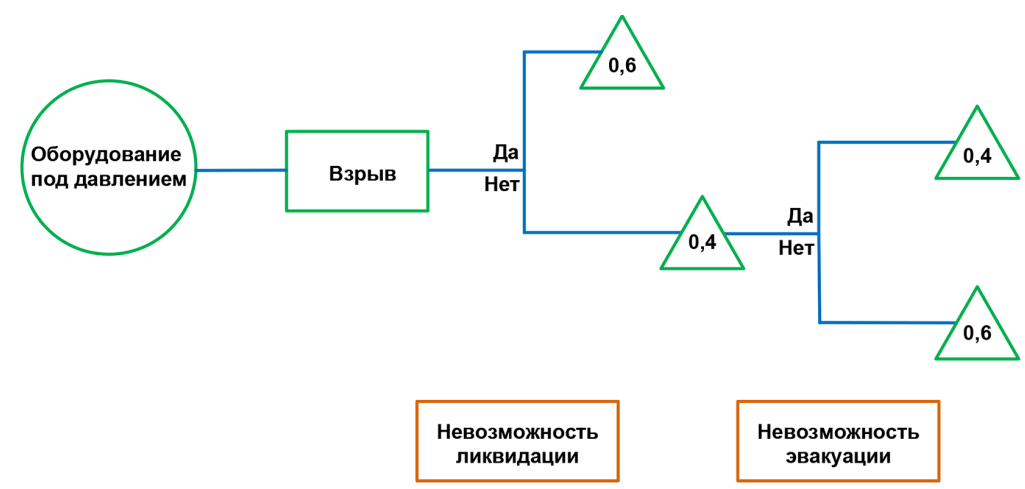

Рис. 3. Дерево событий № 1

Fig. 3. Event Tree № 1

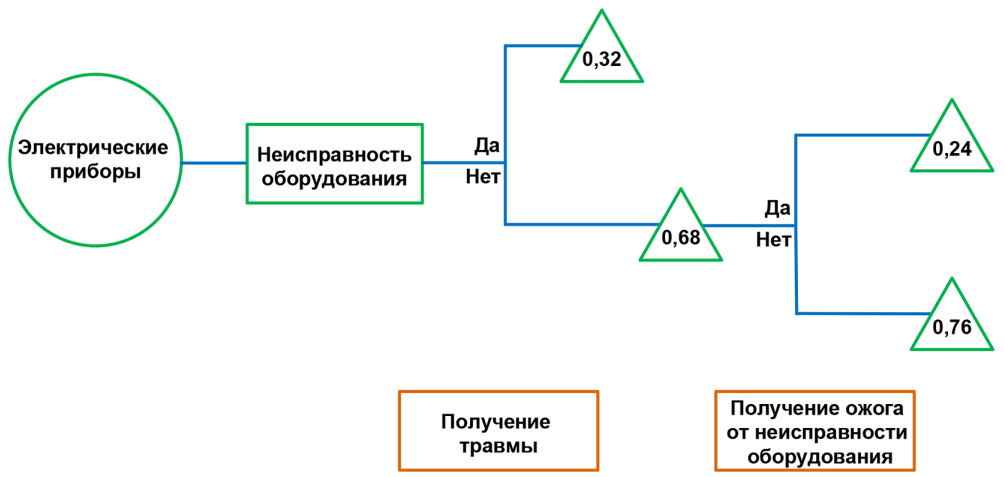

Рис. 4. Дерево событий № 2

Fig. 4. EventTree № 2 


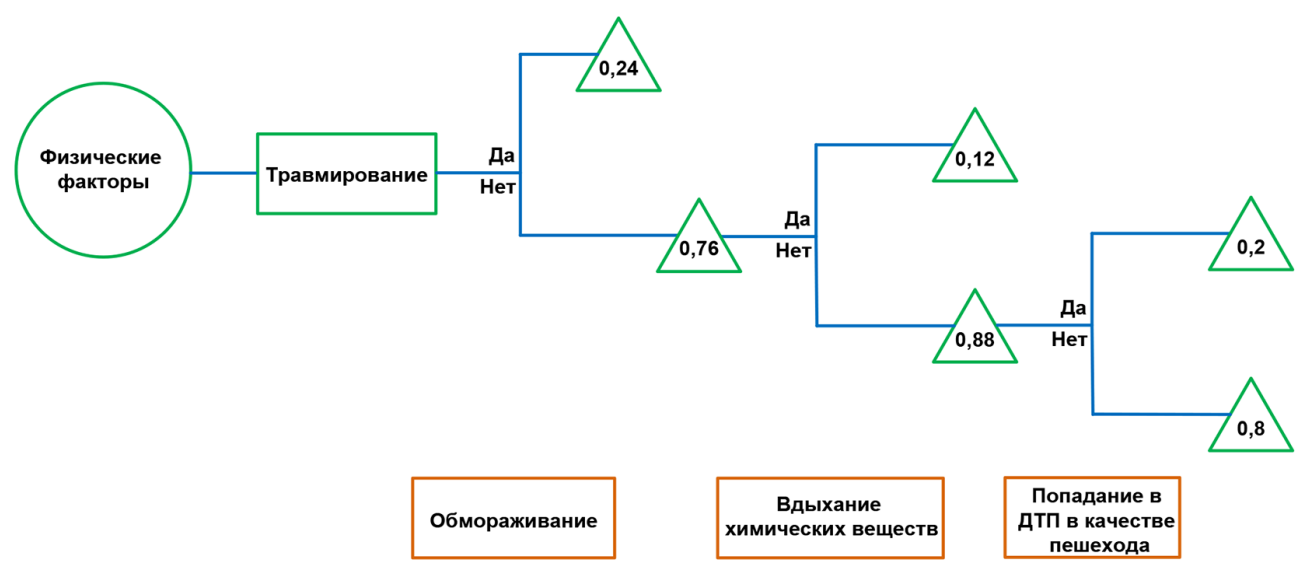

Рис. 5. Дерево событий № 3

Fig. 5. Event Tree № 3

На рис. 5 представлены физические факторы, рассмотрено травмирование при различных обстоятельствах. Так, получение обморожения равно 0,24 , а его отсутствие 0,76 . Вероятность вдыхания химических веществ равна 0,12 , и, наоборот, отсутствие их вдыхания равно 0,88 . Попадание в дорожно-транспортное происшествие в качестве пешехода равно 0,2 и напротив, 0,8 .

\section{Заключение}

Основной проблемный фактор работы машиниста паровых турбин - производственный шум, а его воздействием является риск потери слуха.

В процессе изучения предмета исследования использовался современный метод организации и осуществления государственного контроля, при котором выбор интенсивности (формы, продолжительности, периодичности) проведения мероприятий по контролю, мероприятий по профилактике нарушения обязательных требований определяется отнесением деятельности юридического лица, индивидуального предпринимателя и (или) используемых ими при осуществлении такой деятельности производственных объектов к определенной категории риска либо определенному классу (категории) опасности.

На основании проведения специальной оценки условий труда были произведены расчеты вероятности потери слуха и трудоспособности вследствие воздействия шума. По данным проведения специальной оценки условий труда (СОУТ) была рассчитана сменная доза шума для машиниста паровых турбин 5 разряда. Методика расчета риска ПС от шума соответствует положениям стандарта ИСО 1999.2 (1990), которая учитывает пол, возраст, уровень шума и стаж работы в нем. Была проведена оценка вероятности потери слуха и трудоспособности вследствие воздействия шума по ГОСТУ ГОСТ Р ИСО 1999-2017 для работника 60 лет со стажем 40 лет. Оценка вероятности потери слуха и трудоспособности проводилась по ГОСТ Р ИСО 1999-2017 вследствие воздействия шума для работника 60 лет со стажем 40 лет. В результате полученных данных была выявлена вероятность развития I, II, III степеней ПС. В данном случае она равна 82, 53 и 33 \%, т. е. наиболее вероятно, что у рабочего может быть II или III степень потери слуха.

$$
-533-
$$


Выбор максимально допустимого или максимально безопасного воздействия шума и требований, предъявляемых к защите от шума, а также выбор конкретных формул для оценки вероятности нарушения слуха или для целей возмещения вреда требуют учета этических, социальных, экономических и политических факторов, которые не учитываются в международной стандартизации. В некоторых странах потеря слуха, обусловленная воздействием производственного шума, может повлечь за собой юридические последствия, такие как привлечение к ответственности и выплата компенсаций.

Исходя из этого можно сделать вывод, что на сегодняшний день улучшение условий труда работников является важной государственной социально-экономической задачей, а расчет рисков становится обязательным условием при учете безопасности условий труда.

\section{Список литературы / References}

[1] Андруняк И. В., Логинова А.С. Обеспечение безопасных условий труда машинистов паровых турбин, Вопросы современных технических наук: свежий взгляд и новые решения. Сборник научных трудов по итогам международной научно-практической конференции № 7. Екатеринбург: ИЦРОН, 2020, 43-45. [Andrunyak I. V., Loginova A. S. Ensuring safe working conditions for steam turbine drivers. Questions of modern sciences: a fresh look and new solution. Collection of scientific papers following the results of the international scientific and practical conference № 7. Yekaterinburg. ICRON, 2020, 43-45. (in Russian)].

[2] Андруняк И. В., Логинова А.С. Влияние факторов производственной среды на здоровье машинистов паровых турбин. Наука, образование, производство в решении экологических проблем (Экология-2020). Материалы XVI Международной научно-технической конференции, посвященной 75-летию Победы в Великой Отечественной войне. В 2 т., 2020, 2, 37-40 [Andrunyak I. V., Loginova A. S. The influence of factors of the working environment on the health of steam turbine operators. Science, education, production in solving environmental problems (Ecology-2020). Materials of the XVI International Scientific and Technical Conference dedicated to the 75th anniversary of Victory in the Great Patriotic War. In 2 volumes, 2020, 2 , 37-40 (in Russian)].

[3] Трудовой кодекс Российской Федерации: Федер. закон от 30.12.2001. № 197-Ф3. - Москва, ОТиСС, 2002. (ред. от 09.03.2021), 142 с. [Labor Code of the Russian Federation: Feder. law of 30.12.2001. № 197-FZ. Moscow: OTiSS, 2002. (as amended on 09.03.2021), 142 p. (in Russian)].

[4] Баймишева Т. А., Курмаева И. С. Организация производства. Кинель: РИО Самарская СГСХА, 2018. 204 c. [Baimisheva T. A., Kurmaeva I. S. Organization of production. Kinel: RIO Samara State Agricultural Academy, 2018. 204 p. (in Russian)].

[5] Приказ Минтруда России от 09.12.2014 N997н «Об утверждении Типовых норм бесплатной выдачи специальной одежды, специальной обуви и других средств индивидуальной защиты работникам сквозных профессий и должностей всех видов экономической деятельности, занятым на работах с вредными и(или) опасными условиями труда, а также на работах, выполняемых в особых температурных условиях или связанных с загрязнением» [Order of the Ministry of Labor of Russia dated 09.12.2014 N997n «On Approval of the Model Norms for the Free Distribution of Special Clothing, Special Footwear and Other Personal Protective Equipment to Workers of Through Professions and Positions of All Types of Economic Activity, Employed in Work with Harmful and (or) 
Dangerous Working Conditions also at work performed in special temperature conditions or associated with pollution» (in Russian)].

[6] Федеральный закон «О специальной оценке условий труда» от 28.12.2013 N426-Ф3 (ред. от 30.12.2020) (с изм. и доп., вступ. в силу с 01.01.2021) [Federal Law «On Special Assessment of Working Conditions» of December 28, 2013 N426-FZ (as amended on December 30, 2020) (as amended and supplemented, entered into force on 01.01.2021) (in Russian)].

[7] Захаренков В. В., Олещенко А. М., Данилов И.П., Суржиков Д. В. и др. Новая медицинская технология оценки профессионального риска для здоровья работников промышленных предприятий. Современные наукоемкие технологии, 2013, 9, 136-139 [Zakharenkov V. V., Oleshchenko A.M., Danilov I. P., Surzhikov D. V. etc. New medical technology for assessing occupational health risks for workers at industrial enterprises. Modern high technologies, 2013, 9, 136-139 (in Russian)].

[8] Корж В. А. Специальная оценка поможет снизить издержки [Электронный ресурс]: Режим доступа: https://glavkniga.ru/elver/2014/16/1569-spetsotsenka_pomozhet_sniziti_izderzhki. html/print Заглавие с экрана [Korzh V. A. Special assessment will help reduce costs [Electronic resource]: - Access: https://glavkniga.ru/elver/2014/16/1569-spetsotsenka_pomozhet_sniziti_izderzhki. html/print].

[9] Кислицына В. В., Мотуз И. Ю. Условия труда и показатели профессионального риска нарушения здоровья машинистов котлов и турбин теплоэлектростанции. Современные научные исследования и инновации, 2015, 1, 124-127 [Kislitsyna V. V., Motuz I. Yu. Working conditions and indicators of occupational health risk for operators of boilers and turbines of a thermal power plant. Modern scientific research and innovation, 2015, 1, 124-127 (in Russian)].

[10] Шестаков И. Новая оценка условий труда. Для кого она обязательна уже сейчас и кто может подождать до 2018 года [Электронный ресурc]: - Режим доступа: http://www.lawyercom. ru - Заглавие с экрана. [Shestakov I. New assessment of working conditions. For whom it is obligatory now and who can wait until 2018 [Electronic resource]: - Access: http://www.lawyercom.ru].

[11] Доклад Министерства труда и социальной защиты РФ «О реализации государственной политики в области условий и охраны труда в Российской Федерациив 2014 году» [Электронный pecypc]: - Режим доступа: http://www.rosmintrud.ru/docs/mintrud/salary/24 - Заглавие с экрана [Report of the Ministry of Labor and Social Protection of the Russian Federation «On the implementation of state policy in the field of labor conditions and labor protection in the Russian Federation in 2014» [Electronic resource]: - Access: http://www.rosmintrud.ru/docs/mintrud/salary/24].

[12] Абалдуев В. А. Специальная оценка условий труда: смена терминологии или новое направление государственной политики? Материалы XIV Ежегодной международной научнопрактической конференции юридического факультета МГУ им. М. В. Ломоносова и V Международной научно-практической конференции «Кутафинские чтения» Московского государственного юридического университета им. О. Е. Кутафина «Конституционализм и правовая система России: итоги и перспективыл», 2013, 40. [Abalduev V. A. Special assessment of working conditions: a change in terminology or a new direction of state policy? Materials of the XIV Annual International Scientific and Practical Conference of the Law Faculty of Moscow State University. M. V. Lomonosov and the V International Scientific and Practical Conference "Kutafin Readings» of the Moscow State Law University. O. E. Kutafin «Constitutionalism and the legal system of Russia: results and prospects», 2013, 40 (in Russian)]. 
[13] ТК РФ. Статья 147. Оплата труда работников, занятых на работах с вредными и (или) опасными условиями труда (от 28.12.2013 N421-Ф3) [Labor Code of the Russian Federation Article 147. Remuneration for workers employed in work with harmful and (or) hazardous working conditions (dated 28.12.2013 N421-FZ) (in Russian)].

[14] Левашов С. П. Мониторинг и анализ профессиональных рисков в России и за рубежом. Курган: Издательство Курганского государственного университета, 2013. 345 с. [Levashov S. P. Monitoring and analysis of professional risks in Russia and abroad. Kurgan, Publishing House of Kurgan State University, 2013. 345 p. (in Russian)].

[15] ГОСТ Р 12.0.010-2009 Система стандартов безопасности труда (ССБТ). Системы управления охраной труда. Определение опасностей и оценка рисков. - Введ. 01.01.2011. М, Стандартинформ, 2019, 20 с. [GOSTR12.0.010-2009 Occupational Safety Standards System (SSBT). Occupational safety management systems. Hazard identification and risk assessment. Introduce. 01.01.2011. M, Standartinform, 2019, 20 p. (in Russian)].

[16] Федеральный закон «Об обязательном социальном страховании от несчастных случаев на производстве и профессиональных заболеваний» от 24.07.1998 N125-ФЗ (в ред. Федерального закона от 08.12.2010 N348-Ф3) [Federal Law «On Compulsory Social Insurance Against Industrial Accidents and Occupational Diseases» dated 24.07.1998 N125-FZ (as amended by Federal Law dated 08.12.2010 N348-FZ) (in Russian)].

[17] Национальный стандарт РФ. ГОСТ Р ИСО/МЭК 31010-2011. Менеджмент риска. Методы оценки риска. Risk management. Risk assessment methods. ISO/IEC31010:2009. Risk management Risk assessment techniques (IDT). - Введ. 12.01.2012. М.: Стандартинформ, 2012, 33 c. [National of the Russian Federation. GOST R ISO / IEC31010-2011. Risk management. Risk assessment methods. Risk management. Risk assessment methods. ISO / IEC31010: 2009. Risk management - Risk assessment techniques (IDT). - Introduce. 12.01.2012. M, Standartinform, 2012, 33 p. (in Russian)].

[18] Алексеев С.В., Алиева Р. Х., Амиров Н.Х. и др. Российская энциклопедия по медицине труда. Москва, Медицина, 2005. 413 с. [Alekseev S. V., Alieva R. Kh., Amirov N. Kh., etc. Russian encyclopedia of occupational medicine. Moscow, Medicine, 2005. 413 p. (in Russian)].

[19] Национальный стандарт РФ. ГОСТ Р ИСО 1999-2017. Акустика. Оценка потери слуха вследствие воздействия шума (ISO 1999:2013, IDT). Москва: Стандартинформ, 2017, 24 с. [National of the Russian Federation. GOST R ISO 1999-2017. Acoustics. Assessment of hearing loss due to exposure to noise (ISO 1999: 2013, IDT). Moscow, Standartinform, 2017, 24 p. (in Russian)].

[20] Мушников В. И., Цепелев В. С., Вьюхин В. В., Хоменко А. О. и др. Расчет профессионального риска и потери слуха. Екатеринбург: Уральский федеральный университет имени первого Президента России Б. Н. Ельцина, 2016. 20 с. [Mushnikov V.I., Tsepelev V. S., Vyukhin V. V., Khomenko A. O. etc Calculation of professional risk and hearing loss. Yekaterinburg: Ural Federal University named after the first President of Russia B. N. Yeltsin, 2016. 20 p. (in Russian)].

[21] Искакова А. К., Бакико Е.В. Анализ подходов к оценке профессиональных рисков, Молодежь и XXI век, материалы VI Международной молодежной научной конференции, 2016, 4, 25-27 [Iskakova, A. K., Bakiko E.V. Analysis of approaches to assessing occupational risks, Youth and the XXI century, materials of the VI International Youth Scientific Conference, 2016, 4, $25-27$ (in Russian)].

[22] Измеров Н. Ф. Разработка «Методики расчета индивидуального профессионального риска в зависимости от условий труда и состояния здоровья работника» и «Методики расчета 
интегрального показателя уровня профессионального риска в организации», Актуальные проблемы медицины труда, 2014, 132-162 [Izmerov NF Development of «Methodology for calculating individual occupational risk depending on the working conditions and health status of the employee» and «Methodology for calculating the integral indicator of the level of occupational risk in the organization», Actual problems of occupational medicine, 2014, 132-162 (in Russian)].

[23] Национальныйстандарт РФ. ГОСТ Р МЭК 62502-2014. Менеджмент риска. Анализ дерева событий. - Risk management. Event tree analysis. Введ. 12.01.2015. Москва: Стандартинформ, 2015 [National of the Russian Federation. GOST R IEC 62502-2014. Risk management. Analysis of the event tree. - Risk management. Event tree analysis. - Introduce. 12.01.2015. Moscow, Standardinform, 2015 (in Russian)]. 